\title{
Probiotics and lactose maldigestion
}

\author{
Philip M Sherman MD FRCPC
}

L actic acid-producing bacteria have long been employed in the preparation of a variety of foods and beverages, and are taken on a regular basis by asymptomatic individuals in many parts of the world in an effort to promote and maintain health. More recently, there has been increasing interest in the role of feeding nonpathogenic, viable bacteria to domesticated animals and humans to prevent and treat a variety of intestinal diseases (1) and extradigestive conditions (2).

In the past ten years, it has become apparent that disruptions in genes encoding a variety of immune functions result in inflammation in the gut of mice. However, such immunologic disturbances are critically dependent on the presence of the commensal intestinal microbiota, because germ-free animals with the identical genetic alterations do not develop mucosal inflammation. Dr Karen Madsen and her research group working at the University of Alberta in Edmonton have published well-performed studies showing that the onset of colitis in interleukin-10 deficient mice can be both prevented and treated using a mixture of probiotics (3). As a result, there is renewed interest in the possibility that changes in the microbial flora have a role to play in either the etiology or in influencing the clinical course of chronic inflammatory bowel diseases in humans.

Studies have shown that a combination of probiotic bacteria, given in high numbers, prevent the recurrence and the development of pouchitis in subjects with idiopathic ulcerative colitis who have undergone colectomy and fashioning of a neorectum (4). The idea is that the probiotics induce adaptation of the luminal microflora sufficient to prevent or reduce inflammation in the adjacent gut mucosa. The results of studies undertaken in a randomized and double blinded fashion also have generated interest regarding the potential use of probiotics in other conditions involving the gastrointestinal tract, including, for example, Helicobacter pylori-induced gastritis, Crohn's disease, ulcerative colitis and irritable bowel syndrome (5). Indeed, the field was the subject of an international symposium held in Stockholm, Sweden in September, 2003 (6).

In this issue of the Canadian Journal of Gastroenterology, Yesovitch and colleagues (pp 83-86) from McGill University in Montreal, Quebec undertook lactose breath hydrogen studies in 10 adults with previously documented lactose maldigestion, after which the subjects ingested either $1 \mathrm{~g}(\mathrm{n}=5)$ or $4 \mathrm{~g}(\mathrm{n}=5)$ of a commercially prepared mixture of probiotics. After 17 days of daily ingestion of the probiotics, a $50 \mathrm{~g}$ lactose load was again ingested and a second breath hydrogen study undertaken. There were no differences observed in any of the outcome measures between the two study groups, suggesting to the authors that the ingestion of probiotics may not improve lactose maldigestion. However, the investigators acknowledge that this is a pilot study and may be subject to a type 2 statistical error given the limited number of subjects who were entered into the study. A placebo-treated group of volunteers with documented lactose maldigestion also should be included for comparative purposes in any future related study.

The genetic basis for adult-onset, genetic hypolactasia in humans recently has been clearly defined (7). Nevertheless, there are reports indicating that adaptation does indeed occur in subjects with dietary lactose intolerance following regular daily ingestion of a lactose load (8). In humans, the lactase enzyme is not induced by lactose present in the lumen of the small bowel. Thus, the authors reasonably postulate that an altered gut flora could provide another potential underlying mechanism for this observation. Even though the present study, using the results of lactose breath hydrogen as the primary outcome variable, was negative, it still is possible that a more sensitive and specific marker of lactose absorption would be able to detect differences following a defined course of probiotics.

Measurement of microbial beta-galactosidase activity present in both the commercial probiotic preparation and in fecal samples of study subjects also might be undertaken in future studies. Such analyses would help to confirm the presence of metabolically active bacteria in the ingested product and in the lumen of the colon following the ingestion of probiotics. In this regard, it is also of considerable interest to know more details about the number and species of probiotic bacteria that were identified by Yesovitch and colleagues in random cultures of the commercial probiotic preparation.

A secondary goal of the study by Yesovitch and colleagues was to determine if the results of lactose breath hydrogen studies could be employed as a surrogate marker of successful colonization of the bowel with ingested probiotics. Again, the negative results in this pilot study are interpreted by the authors as an indication that breath hydrogen testing is not the 
way to go. However, a more detailed evaluation with specific probiotics, prebiotics or synbiotics (that is, a mixture of probiotics and prebiotics) likely is required before discarding a potentially useful and noninvasive method for evaluating the gut microbiota.

The field of probiotics has been plagued by contradictory findings in studies undertaken in a variety of settings. Such variability in results may well relate to differences in the choice of specific organisms employed as the probiotic to be tested. In addition, the number of viable bacteria delivered to the site of action also could have an impact on measurable outcomes.

Additional studies are now required to clearly define the mechanisms by which probiotics exert their potentially beneficial effects in the gut and in extraintestinal conditions including, for example, atopic disorders (9). Only in this way can a

\section{REFERENCES}

1. Huang JS, Bousvaros A, Lee JW, Diaz A, Davidson EJ. Efficacy of probiotic use in acute diarrhea in children: A meta-analysis. Dig Dis Sci 2002;47:2625-34.

2. Reid G, Jass J, Sebulsky MT, McCormick JK. Potential uses of probiotics in clinical practice. Clin Microbiol Rev 2003;16:658-72.

3. Madsen K, Cornish A, Soper P, et al. Probiotic bacteria enhance murine and human intestinal epithelial barrier function. Gastroenterology 2001;121:580-91.

4. Gionchetti P, Rizzello F, Helwig U, et al. Prophylaxis of pouchitis onset with probiotic therapy: a double-blind, placebo-controlled trial. Gastroenterology 2003;124:1535-8.

5. Hamilton-Miller JMT. The role of probiotics in the treatment and prevention of Helicobacter pylori infection. Int J Antimicrob Agents 2003;22:360-6.

6. Probiotics in gastric and intestinal disorders as functional food and more rational and targeted development of the optimal choice of microbe for use in a probiotic regimen be undertaken. The future of probiotics as an option for use in the armamentarium of medical treatments appears to be bright. As noted by Dr Tom LaMont, "The therapeutic possibilities of manipulating the bowel flora are just beginning to reach clinical development." (10). Advances both in the laboratory and in the clinical research setting will help to bring this prediction to fruition in the near future.

ACKNOWLEDGEMENTS: PMS is the recipient of a Canada Research Chair in Gastrointestinal Disease. Work in the author's laboratory is funded by the Canadian Institutes of Health Research, the Crohn's and Colitis Foundation of Canada, and was previously supported by a research contract awarded from Institut Rosell-Lallemand Inc.

medicine. Arranged in connection with the 16th International Workshop of the European Helicobacter Study Group, Stockholm, Sweden, September 2-3, 2003:1-61.

7. Troelsen JT, Olsen J, Moller J, Sjostrom H. An upstream polymorphism associated with lactase persistence has increased enhancer activity. Gastroenterology 2003;125:1686-94.

8. Pribila BA, Hertzler SR, Martin BR, Weaver CM, Savaiano DA. Improved lactose digestion and intolerance among AfricanAmerican adolescent girls fed a dairy-rich diet. J Am Diet Assoc 2000;100:524-8.

9. Kalliomaki M, Salminen S, Poussa T, Arvilommi H, Isolauri E. Probiotics and prevention of atopic disease: A 4-year follow-up of a randomised placebo-controlled trial. Lancet 2003;361:1869-71.

10. LaMont JT. The renaissance of probiotics and prebiotics. Gastroenterology 2000;119:291. 


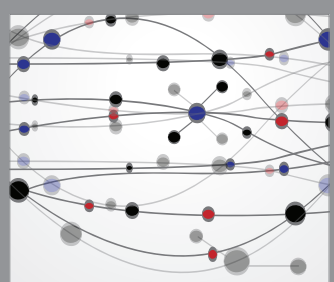

The Scientific World Journal
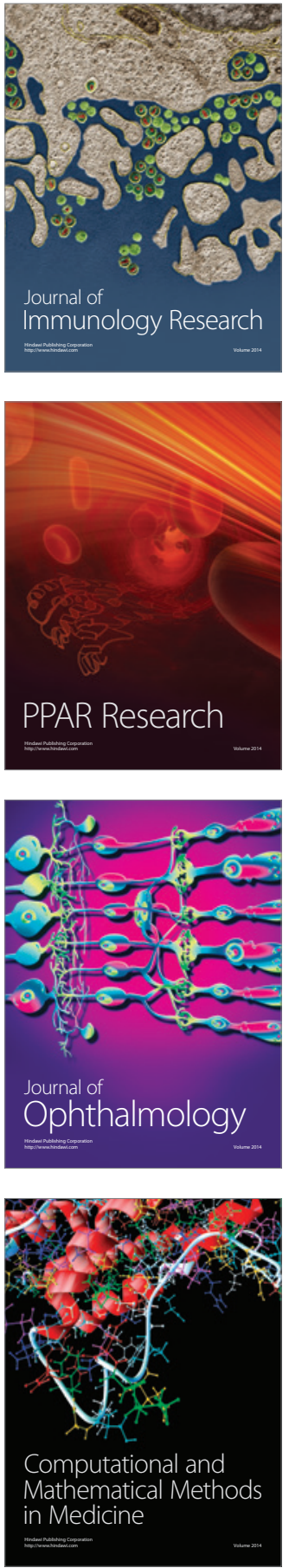

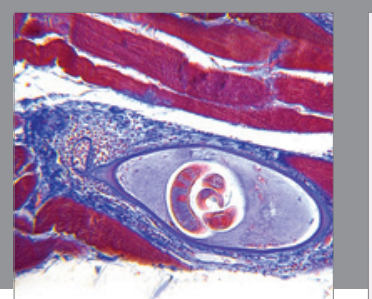

Gastroenterology Research and Practice

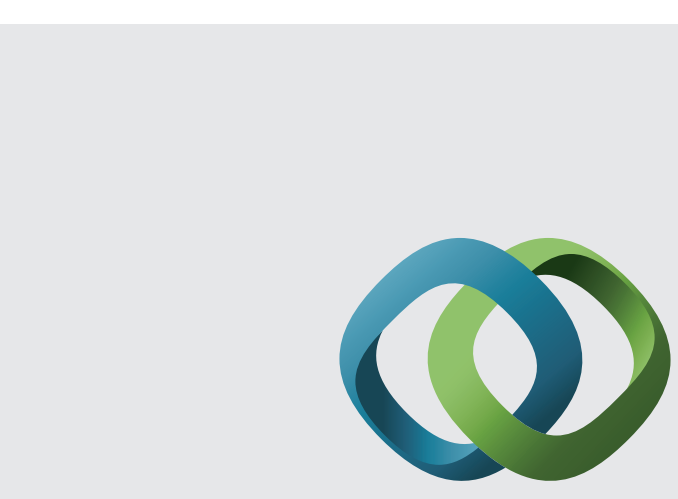

\section{Hindawi}

Submit your manuscripts at

http://www.hindawi.com
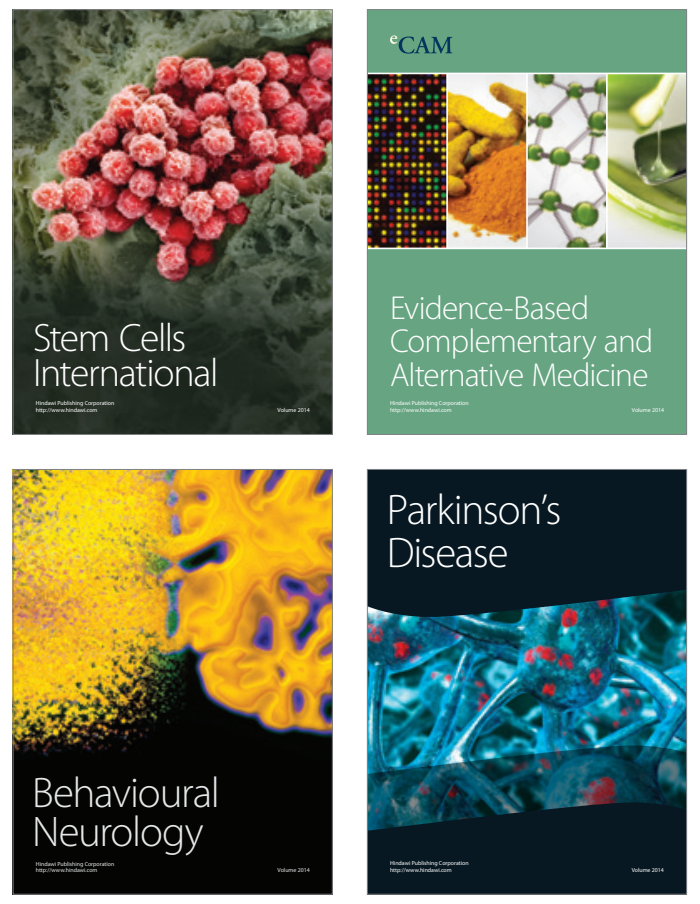
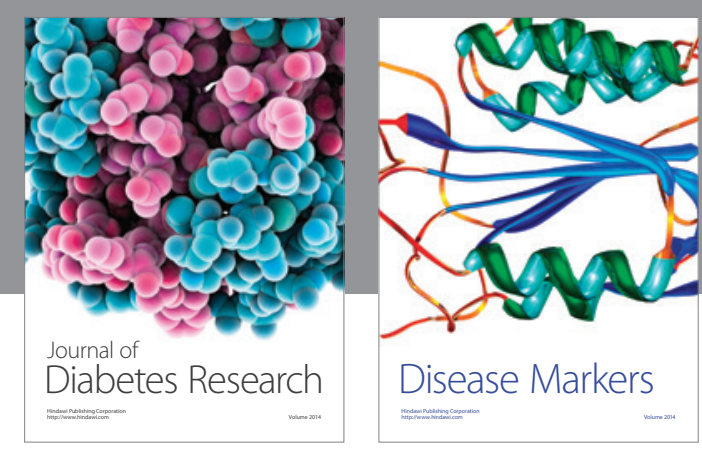

Disease Markers
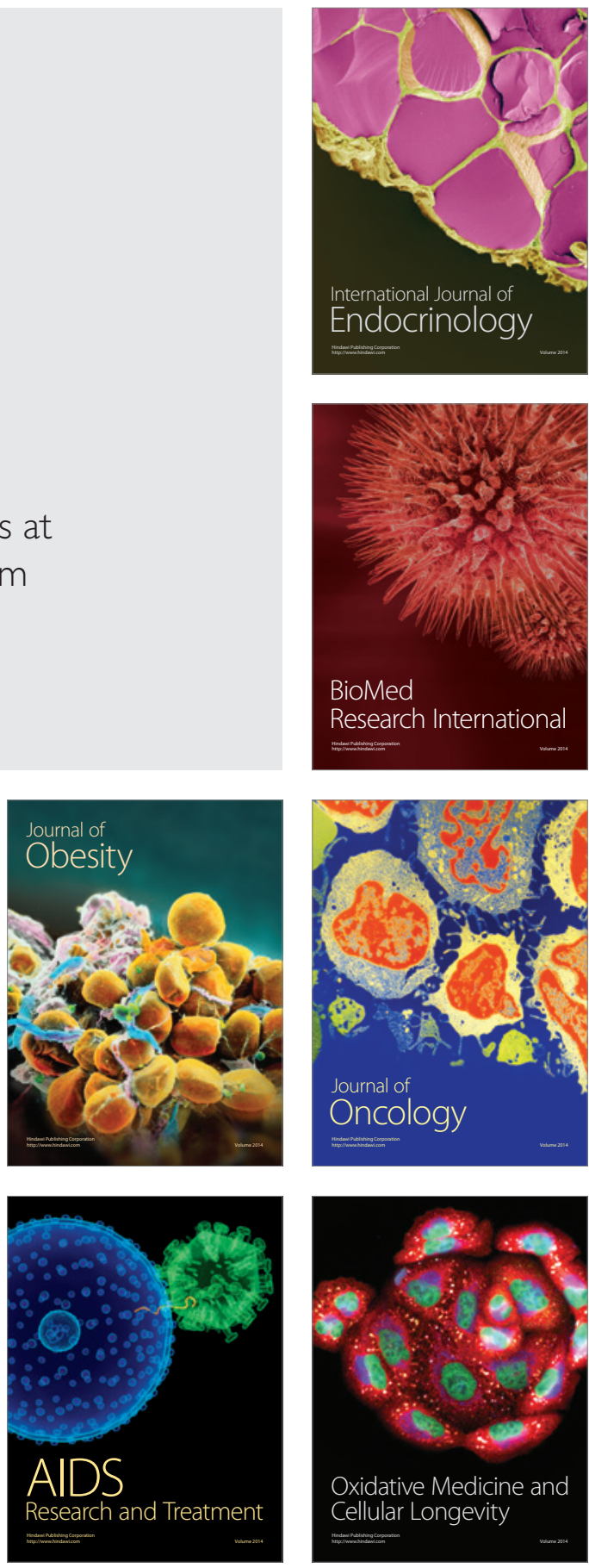